\title{
Harnessing the Solar Energy in Extracting Essential Oil for Community Based Perfumery and Aromatherapy
}

\author{
Agnes R. Pesimo \\ Partido State University, Goa, Philippines \\ Email: agnespesimo@yahoo.com
}

How to cite this paper: Pesimo, A.R. (2017) Harnessing the Solar Energy in Extracting Essential Oil for Community Based Perfumery and Aromatherapy. Open Access Library Journal, 4: e3905. https://doi.org/10.4236/oalib.1103905

Received: August 23, 2017

Accepted: November 19, 2017

Published: November 22, 2017

Copyright $\odot 2017$ by author and Open Access Library Inc.

This work is licensed under the Creative Commons Attribution International License (CC BY 4.0)

http://creativecommons.org/licenses/by/4.0/

\section{cC) (i) Open Access}

\begin{abstract}
The study is focused on the use of solar energy in extracting essential oil as alternative process of extracting essential oil. In particular, it determined the rate of extraction and percent yield at normal temperature and weather condition. Four kinds of plant samples with known aromatic characters and pharmaceutical importance, Sambong (Conyza balsamifera Linn), Oregano (Plectranthus amboinicus, Lour.), Lemongrass (Cymbopogon citrates) and Roses (Rosa damascena) were used as samples. The plant samples were air dried and weighed and then transferred to the designed solar essential oil extractor. The rate of extraction was measured in terms of the volume of plant extract per day expressed in $\mathrm{ml} /$ day and the percent yield was measured in terms of the ratio between volume of plant extracts and the mass of plant samples multiplied by $100 \%$. Results showed that it is possible to extract essential oil from plants using the sun as source of energy. The rate of extraction varies with the plant samples with oregano as the fastest $(3.4 \mathrm{ml} /$ day $)$ and rose petals the slowest $(1.8 \mathrm{ml} /$ day). The essential oil extraction process can last for 9 days. The percent yield of plant extracts varies with the kind of plant samples with sambong (Conyza balsamifera Linn) having the highest percent yield (72\%) and rose petals (Rosa damascena) the lowest (18.5\%).
\end{abstract}

\section{Subject Areas}

Green Chemistry

\section{Keywords}

Harnessing, Solar Energy, Essential Oil, Community Base, Perfumery and Aromatherapy 


\section{Introduction}

Aromatherapy is all about the practice of using essential oil to soothe the physical body and the mind when inhaled or massaged in one's human body. Aromatherapy is also known as Essential Oil therapy because it uses essential oils from plant and animals containing aromatic substances. It is widely used to balance, blend and stimulate the body and mind. It is used by many as a stress reliever, a pain reliever and a healer. These compounds affect the human body psychologically and physically by reducing anxiety and improving the mood, conquering body pain and mental depression. The aromatic characteristics of essential oils supports physical, emotional, and spiritual health trough their therapeutic effect.

Aromatic compounds found in essential oils are volatile substances that would readily evaporate even at room temperature. These are the scents found in perfumes, foods additives and recently, they are used as additives in consumer products such as body wash, soap and detergents, cosmetics to improve quality. These aromatic compounds are nonpolar and therefore immiscible in water. Essential oils do not just contain one kind of aromatic compound but a complex mixture of many different kinds of aromatic substances making essential oils a complex but pure extracts from plants which cannot be replicated in a laboratory. The chemistry of essential oils consists of simple hydrocarbons, oxygenated hydrocarbons, and their isomers. The composition of essential oil from a plant variety could be affected by geographical location, climatic conditions, and extraction process.

The Philippines is endowed with a rich variety of plants which can be used for aromatherapy and perfumery. Stuart [1] has 1060 entrees of medicinal plants with defined aromatic, medicinal and therapeutic uses. Among those plants considered in this study are sambong or lakadbulan (Conyza balsamifera Linn), oregano (Origanum heracleoticum L), lemongrass (Cymbopogon citrates) and roses (Rosa damascena) (Figure 1). These plants also contain essential oils unique to each other.

Sambong or Lakadbulan (Conyza balsamifera Linn) belongs to family Gramineae. It is a half woody, strongly aromatic shrub, densely and softly hairy, 1 to 4 meters high. Stems grow up to 2.5 centimeters in diameter. Leaves are simple, alternate, elliptic- to oblong-lanceolate, 7 to 20 centimeters long, toothed at the margins, pointed or blunt at the tip, narrowing to a short petiole which are often auricled or appendaged. Flowering heads are stalked, yellow and numerous, 6 to 7 millimeters long, and borne on branches of a terminal, spreading or pyramidal leafy panicle. Discoid flowers are of two types: peripheral ones tiny, more numerous, with tubular corolla; central flowers few, large with campanulate corolla. Involucral bracts are green, narrow and hairy. Anther cells tailed at base. Fruits are achenes, dry, 1-seeded, 10-ribbed, hairy at top. It functions as an astringent and as an expectorant, and has been found to be anti-diarrhea and anti-spasm [1]. Analysis of leaf revealed 50 components contributing to $99.07 \%$ of the oil: Borneol (33.22\%), caryophyllene (8.24\%), ledol (7.12\%), tetracyclo- 


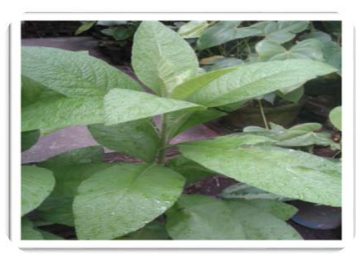

(a) Sambong or Lakadbulan ( Conyza balsamifera Linn)

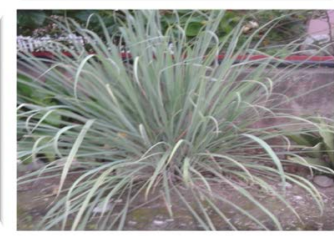

(c) Lemongrass (Cymbopogon citrates)

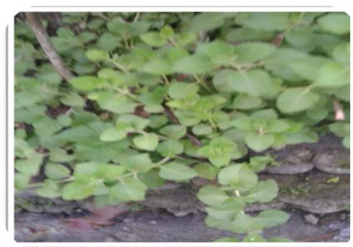

(b) Oregano

(Plectranthus amboinicus, Lour.)

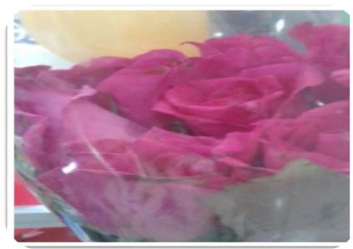

(d) Roses

(Rosa damascena)

Figure 1. Medicinal plants with aromatic and therapeutic properties used in this study.

$[6,3,2,0,(2.5) .0(1.8)$ tridecan-9-ol, 4,4-dimethyl (5.18\%), with phytol (4.63\%), caryophyllene oxide(4.07\%), guaiol (3.44\%), thujopsene-13 (4.42\%), dimethoxydurene (3.59\%) and $\gamma$-eudesmol (3.18\%) [2].

Oregano also known as suganda (Plectranthus amboinicus, Lour.) belongs to the family Lamiaceae. It is an erect, spreading, branched, rather coarse, strongly aromatic, green herb, with fleshy stems. Leaves are fleshy, broadly ovate, 4 to 9 centimeters long, often heart-shaped, and somewhat hairy, with rounded toothed margins, with the tip and base decurrent. Flowers are small, and occur in distant whorls. Calyx is bell-shaped; the throat is smooth inside, with two lips, the upper lip being ovate and thin, the lower lip having four narrow teeth. Corolla is pale purplish and 5 times longer than the calyx, with a short tube, inflated throat, and short lips. The volatile oils in oregano and its properties are believed to be responsible for slowing the process of spoilage of food and thus minimizing the risk of ingesting harmful bacteria, parasites and fungi [1]. Chemical Analysis of the plant showed that it contains pinene, camphene, 1-octen-3-ol, 3 octanone, myrcene, phellandrine, 3-carene,terpinene, p-cymene, limonene, ociemne, y-terpinene, sabinene hydrate trans, terpinolene, linalool, isoborneol, 4-carvomenthenonol, a-terpineool, dehydrocarvone (trans), carvacrol methyl ether, carvone, anethole, thymol, carvacrol, $\beta$-caryoplhyllene, inalylbutirate, $\gamma$-muurolene, $\beta$-bisabolene $\gamma$-cadinene, $\delta$-Cadinene spathulenol, caryophyllene oxide, humulene epoxide II [3].

Lemongrass (Cymbopogon citratus DC.) or commonly called as tanglad belongs to the family Gramineae. It is a tufted and perennial grass. Leaves grow to a length of up to 1 meter, about 1 to 1.5 centimeters wide, scabrous, flat, longacuminate, and smooth. Panicles are 30 to 80 centimeters long, interrupted below; the branches and branchlets somewhat nodding. Perfect spikelets are linearlanceolate, pointed, not awned, and about 6 millimeters long. The oils are reddish- 
yellow with an intense odor and taste of lemons. It is carminative, tonic, stimulant, diuretic, purgative, sudorific. Its leaves are considered antimicrobial, antiinflammatory and sedative. and possess pharmacologic activities such as antimalarial, antimutagenicity, antimycobacterial, antioxidants, hypoglycemic and neurobehavioral. Chemical analysis showed that Tanglad contains Neral (citral A), 40.33\%; geranal (Citral B) 41.67\%, myercene, 2 terpenene, linalool, nerol, borneol, methyl geranate, geranyl acetate, methyl-1,2,4-decadienoate, n-hexadecane, a-cardinol, hexadecanoate [4].

Roses (Rosa damascena) belongs to the family Rosaceae. The Damask rose, Rosa damascena, dates back to 900 BC. It is the national flower of Iran and has been called the "Flower of the Prophet Mohammad." The use of rose oil dates back to ancient Persia. Petal steam distillation produces rose water and rose oil and about 2000 petals yield a mere drop of rose oil. It is one of the most extensive genus in the plant kingdom, with some botanical reports of over 4000 species. A prickly shrub, most grow upright, some are creeping. Flowers are yellow, white, pink or red, solitary or in branched clusters or corymbs at the end of short branches. four to five petals and sepals. Leaves are alternate, pinnnate, usually with five to nine leaflets with a terminal leaflet. Fruits are usually fleshy and berrylike at maturity [1]. The volatile oil obtained by hydro distillation of the petals of Rosa damascene Mill. (Rosacea) was analyzed by gas chromatography/mass spectrometry (GC/MS). Fifty compounds representing 99.06\% of the oil were characterized. The volatile oil was found rich in sesquiterpenes and aliphatic components, consisting of two monoterpenic esters $(0.44 \%)$, nineteen sesquiterpenes (44.05\%), twenty nine aliphatic compounds (54.57\%) including n-octadecanol, n-hexacosane, n-octacosane and n-nonacosane (26.31\%) [5]. Health benefits are antidepressant, antiphlogistic, antiseptic, antispasmodic, antiviral, aphrodisiac, astringent, bactericidal, cholagogue, cicatrisant, depurative, emenagogue, haemostatic, hepatic, laxative, nervine, stomachic and uterine substance [6]

There are many methods of essential oil extraction, the most popular being steam distillation. Other methods include expression, effleurage, maceration, and solvent extraction. Other extraction methods have been tried using compressed $\mathrm{CO}_{2}$ [7], instant controlled pressure drop technology [8], enfleurage and solvent extraction methods [9], Microwave Extraction [10], extraction of essential oils from jasmine flower using solvent extraction method [11]. Solar distillation was already used by Hensel and Munir [12] and decentralized solar distillation was used as alternative method that contribute to rural development. Flavourtech, [13] used the spinning cone column for steam essential stripping of essential oils and Huynh [14] used the supercritical carbon extraction and steam distillation method. Such methods requires complicated processes and set up. Only highly technical and trained people are required to operate the process.

The economics of essential oil shows that there is high demand for this product including the Philippines. The production would normally depend on both the cultivation of the herbs and extraction of oils from the herbs. The cost of cul- 
tivation of herbs in the developing countries per hectare is estimated at US \$ 500 to 1000 and the revenue is from essential oils after the extraction per hectare is estimated to be around US \$ 3000 to US \$ 6000 [15]. The demand is from end use industries distributed to personal care products, food products, pharmaceuticals $60 \%$, flavour industry $20 \%$ and pharmaceutical industry $20 \%$. The global essential oil market size exceeded USD 6.0 billion in 2015 and its increasing applications in aromatherapy coupled with rising demand for fragrances and flavors in food and beverages and personal care is expected to drive market growth over the forecast period [16]. The existing demand for citronella oil in Cebu City, Philippines alone is estimated at 3,000 to 4,000 liters per month. The total available local supply as produced by Tuburan and Boljoon is only about 300 liters. The rest of the industry, requirements are sourced out from imports [17]. This existing demand supply can be addressed by designing a simple and low cost process of extracting essential oils, in such a way that the transfer of technology can be readily adopted by local farmers.

The Bicol Region does not produce essential oils on large scale and there is no existing industry for essential oil in spite of its abundant and diverse aromatic plants. One reason is the complexity of essential oil extraction and the large volume of plants and herbs to produce little amount of essential oil. Steam distillation, a common method of essential oil extraction requires a lot of skills and technical expertise and understanding. The set up is difficult to assemble and requires energy to do the entire process. Designing a simple essential oil extraction process with the sun as the source of energy can strengthen the production of essential oil and capacitate the farmers in the countryside to engage in essential oil production. Capability building among farmers on essential oil extraction can complement the high demand of essential oils in different parts of the country and the world.

\section{Objectives}

The main purpose of the study was to explore on the possibility of extracting essential oil from selected aromatic plants using the solar energy as the power source. In particular, the study designed a simple solar power essential oil for use by the community in the rural area using low cost materials. The efficiency of the designed essential oil extractor was measured in terms of the rate of extraction and the percent yield. It also characterized the extracted essential oil in terms of its physical characteristics and compared them with the commercial essential oil.

\section{Methodology}

Selection of plant samples. Herbs used in this study are common and abundant in the locality and known to contain essential oils and with pharmaceutical and aromatic properties. The plant samples used in the extraction using the solar energy are the aromatic plants available in the locality which are the sambong 
(Conyza balsamifera Linn)., oregano(Cymbopogon citratus DC), lemongrass (Cymbopogon citratus DC.) and roses. The plants were collected from the backyard except for roses which was bought from the market. The chosen plants were authenticated through the Philippine Medicinal Plants by Stuart [1] where detailed description of the plant samples used were given and were further confirmed by our Biologists.

Material Preparation. Four species of aromatic plant samples were collected The plant samples were cut into $5 \mathrm{~cm}$ length, air dried, weighed and then transferred to the designed solar essential oil collector.

Experimental Set Ups. The extraction of essential oil through solar energy was done in a trial and error method until the final and appropriate set up was met. The first experimental set up used a 1.0 transparent bottle with a plastic cap. The plant samples were placed inside the bottle, tightly closed and exposed under the heat of the sun for several days. In this set up, the evaporation of the essential oil from the plant sample was observed because of the droplets of liquids formed at the sides of the bottle. This droplets combine with other droplets and precipitated at the bottom of the bottom of the bottle. The precipitate is the plant extract containing the essential oil. The plant extracts were collected, measured and kept in another clean and smaller container. In this set up, the precipitated essential oil mixed up with the plant samples.

To avoid the contamination of the essential oil with the plant samples, another set up was tried. In the second experimental set up, the bottle was inverted and a wire mesh with $0.5 \mathrm{~cm}$ distances was inserted into the bottle to separate the extracted essential oil from the plant samples and to prevent them from getting in contact with each other. The plant samples were on top of the bottle and the extracted essential oil settled at the bottom of the bottle neck. The inverted bottle was placed on the porcelain cup to serve as the collecting vessel for the extracted essential oil. The bottle was not covered to allow the plant extract to flow freely to the collecting vessel. In this set up, there was a difficulty of putting the plant samples into the bottle so another experimental set up was tried.

In the third experimental set up, a wide mouthed, high density polyethylene jar was tried. A wire mesh with $0.5 \mathrm{~cm}$ distances was used and placed in the upper part of the jar to separate the plant samples and the extracted essential oil.. It also holds the plant samples not to fall at the cover when inverted. In this set up, the samples were placed in the container and when filled up, the wire mesh was placed near the mouth of the container. The container is then covered, inverted and exposed under the heat of the sun. The plant samples and the plant extracts were successfully separated but collecting the extracted essential oil is difficult.

To address the problem of collecting the extracted essential oil, the cover of the wide mouthed container was removed and attached with a conical container that served as the funnel. This allows the plant extracts to flow freely down the essential oil collector. To make the set up stand freely, a wooden base was connected to the set up. A hole equal to the diameter of the cover of the container 
was made on top of the wooden base and the funnel was inserted into the hole, the essential oil collector was connected to the funnel. The funnel has a reseal able cap which can be opened to collect the essential oil.

The final set up was used in collecting samples for the rate of extraction, percent yield and for the characterization of the essential oil. Three trials were made for each data to be collected.

Measuring the rate of essential oil extraction. The amount of essential oil extracted from plant samples was measured daily and the rate of extraction of plant samples were measured using the formula:

$$
\operatorname{Re}=V t / T t
$$

where: $R e=$ Extraction Rate

$V t=$ total volume of extract $(\mathrm{ml}) /$

$T t=$ total days extraction

Measuring the Percent Yield. The percent yield of extracted essential oil was measured using the graduated cylinder and the mass of the plant samples were measured using a digital balance. The percent yield was calculated by dividing the volume of the extracted essential oil by the mass of the plant samples and expressed as percent yield in volume per mass (\%).

$$
\% Y=V / m
$$

where: $\% Y=$ Percent Yield

$V=$ volume of extracted essential $(\mathrm{ml})$

$m=$ mass of plant sample $(\mathrm{g})$

Characterization of the Plant Extracts. The physical characteristics of the plant extracts were determined by its color, odor, viscosity and other notable characteristics through sensory evaluation. These were compared with the commercial essential oil.

\section{Results and Discussion}

The Rate of Extraction. The extraction process is described qualitatively and quantitatively. Qualitative discussion includes the color changes of the plant samples before, during and after the extraction process. It also describes the physical characteristics of the plant extracts in terms of color, odor, and other notable characteristics. Quantitative observation includes the rate at which essential oils are produced and the percent yield of essential oils.

Rate of extraction of essential oils from plant samples. The rate at which the volatile essential oils were extracted from the plant samples is presented in Figure 2.

Figure 2 shows the extraction rate of the essential from the plant samples. The extraction rate was calculated using Equation (1). Oregano has the highest extraction rate $(3.6 \mathrm{ml} /$ day $)$ followed by lemongrass $(3.4 \mathrm{ml} /$ day $)$, sambong $(2.6$ $\mathrm{ml} /$ day) and the lowest is rose $(1.8 \mathrm{ml} /$ day $)$. The graph also shows that there is a rapid rate of extraction from the first day to the ninth day and after the ninth day, the rate of extraction was already less than $0.1 \mathrm{ml}$, an indication that at this 


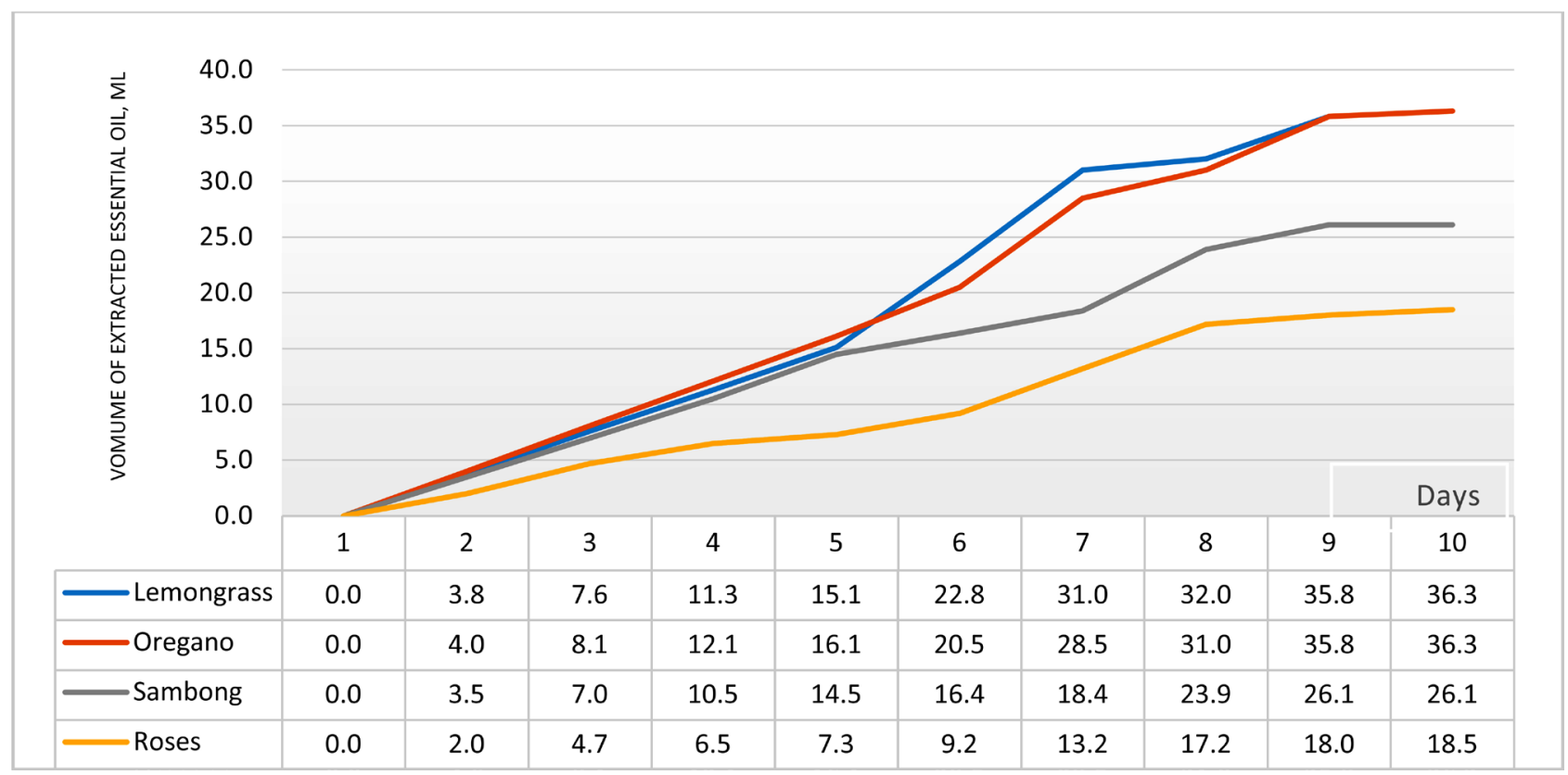

Figure 2. Rate of extraction of essential oils from different plant samples.

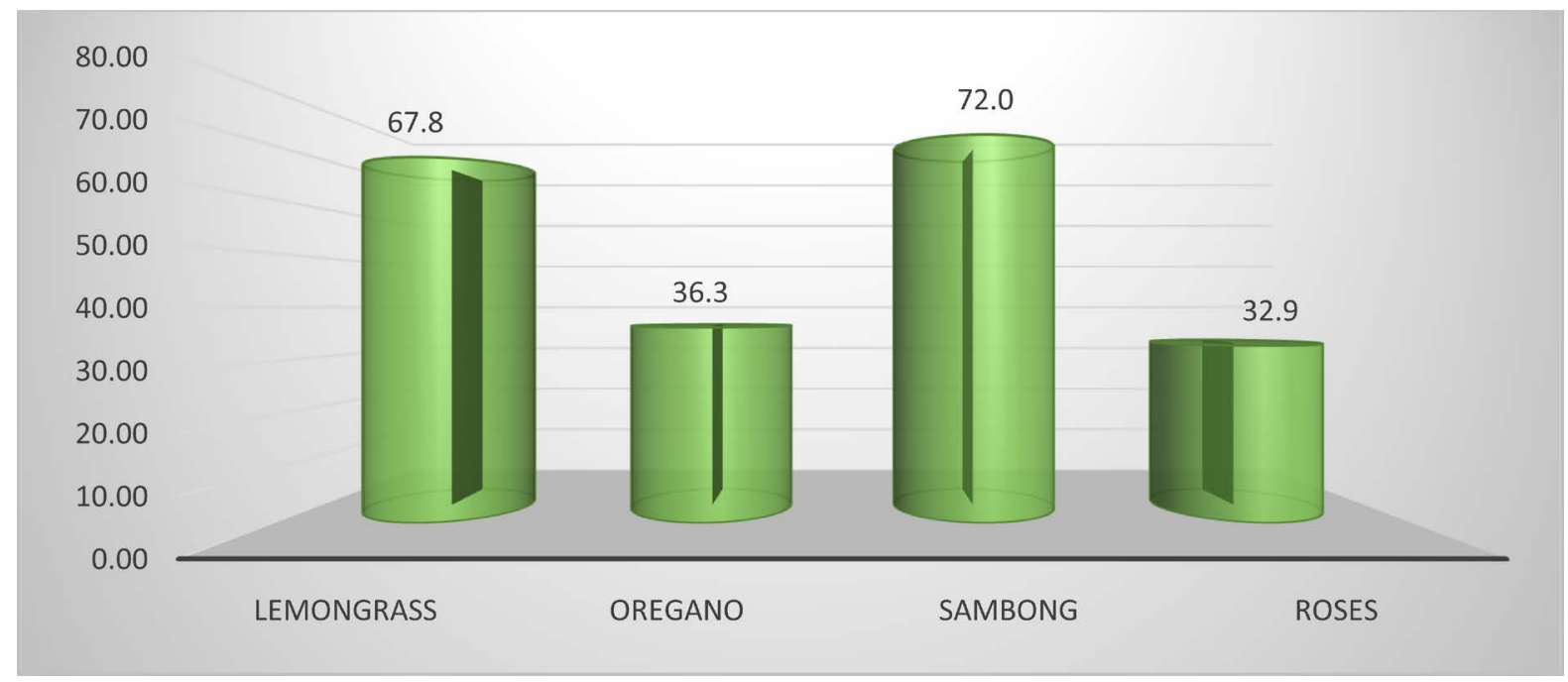

Figure 3. Percent yield of plant extracts from lemongrass, oregano, sambong and roses.

point the evaporation of the volatile essential oil has already declined and therefore extraction process can be stopped. This further implies that the extraction of essential oil using the solar energy took 9 days for all the plant samples.

Percent Yield. The percent yield of the extracted essential oil determined the amount of the extracts that were collected from the plant sample. The percent yield tells the amount of plant extracts that can be harvested from a plant samples expressed in $\mathrm{ml} / \mathrm{g}$. It was computed using Equation (2). Figure 3 shows the percent yield of plant extracts of lemongrass, oregano, sambong and roses.

The total yield of the plant extracts, shows that sambong has the highest percent yield $(72.0 \%)$, followed by lemongrass $(67.82 \%)$, oregano $(36.3 \%)$ and the least is roses $(32.89 \%)$. It can be seen that there is variability in the amount of 
plant extracts and this depends on the kind of leaves the plant has. The low yield of rose oil explains why it is considered the most expensive essential oil in the market. The percent yield of rose petal produced by the essential oil company is $0.006 \%$, oregano is $1.2 \%$ indicating that the plant extract is a combination of hydrosol and pure essential oil. A large amount of plant sample is needed to obtain the desired amount of pure essential oil. This means that to obtain a $5 \mathrm{ml}$ of pure rose oil, a $15.2 \mathrm{~g}$ of rose petals are needed. If a $10 \mathrm{ml}$ rose oil costs US $\$ 28.50$ [18], the cost of a $1000 \mathrm{ml}$ of rose oil is $\$ 1339.5$ or Php 62,956.5. This implies that there is high demand for rose flowers requiring farmers to grow more roses but the cost of essential oil is very promising and there's the abundance of aromatic plants and herbs in the region. The same implication can be true to sambong, oregano, lemongrass and other aromatic plants This means that perfumery and aromatherapy is a promising industry for the Bicol Region, a place where almost all plants with essential oil character abounds. This will benefit farmers, women and laborers by giving them alternative sources of income. It will benefit people in all walks of life by making essential oil accessible to the community.

Characteristics of the Plant Extracts. What was extracted in this study was a mixture of hydrosols and essential oils. Normally, the plant extract is a mixture of essential oil and hydrosol and further purification process or separation technique using the separatory funnel is required to get the pure essential oil from the plant extracts. Table 1 below shows the comparative charactersitics of the plant extracts with the commercial essential oil.

As noted in Table 1, there is similarity in the physical characteristics of the

Table 1. Characteristics of plant extracts compared with the commercial essential oils.

\begin{tabular}{|c|c|c|c|}
\hline Plant Extracts Essential Oil & Characteristics of Commercial Essential Oil & $\begin{array}{l}\text { Description of extracted } \\
\text { essential oil }\end{array}$ & $\begin{array}{c}\text { Picture/sample of } \\
\text { extracted essential oil }\end{array}$ \\
\hline Lemongrass oil & $\begin{array}{l}\text { Lemongrass oil has a lemony, sweet smell and is } \\
\text { dark yellow to amber and reddish in color, with } \\
\text { a watery viscosity. }\end{array}$ & $\begin{array}{c}\text { The color is amber, watery } \\
\text { viscosity with sweet lemon } \\
\text { odor. }\end{array}$ & \\
\hline Oregano Oil & $\begin{array}{c}\text { Oregano oil has a powerful, spicy, camphor-like } \\
\text { aroma, is pale yellow in color and medium to } \\
\text { watery in viscosity. [18] }\end{array}$ & $\begin{array}{l}\text { yellow, watery viscosity and } \\
\text { with strong aroma (oregano) } \\
\text { odor. }\end{array}$ & \\
\hline Rose Oil & $\begin{array}{l}\text { Orange yellow or orange reddish or slightly olive } \\
\text { yellowish viscous liquid of extremely rich warm, } \\
\text { spicy floral with a very deep rose odor. [19] }\end{array}$ & $\begin{array}{l}\text { Orange Yellow in color with } \\
\text { sweet rosy odor and watery in } \\
\text { viscosity. }\end{array}$ & \\
\hline Sambong Oil & White, watery in viscosity with fresh smell [18] & $\begin{array}{l}\text { White, watery viscosity, fresh } \\
\text { aromatic (sambong) odor }\end{array}$ & \\
\hline
\end{tabular}


plant extracts with the corresponding properties of oil in the literatures of commercial essential oils. This is an indication that the plant extracts possess similar characteristics with the commercial essential oil and this confirms the success of extracting essential oil using the designed process. This means that the plant extract in itself can already be used in various application. It was noted that long exposure of essential oil to sunlight causes some considerable changes in color resulting to the destruction of its physical characteristics.

Three factors that affected the quality of essential oils are sunlight, temperature and air. Sunlight increases the deterioration of essential oils and carrier oils through oxidation. Sunlight and oxygen cause carrier (vegetable oils) to gradually turn rancid, which also makes an aromatherapy blend unsuitable for use. Electric light can also contribute to the deterioration of essential oil. Essential oils should therefore be stored at cool or room temperatures to about five degrees centigrade to help increase their shelf life. Air reacts with the chemicals of essential oils and can irreversibly change their composition and color. Oxidation can also turn carrier (vegetable) oils rancid, which will contaminate the whole aromatherapy blend. All essential oil containers should be air tight to prevent the oxidation of the oils. [20]. The plant extracts should not be over exposed to light and should be kept in tightly sealed and dark container to avoid deterioration of the plant extracts, prolong its shelf life and prevent rapid oxidation.

\section{Conclusions}

This study concludes that it is possible to extract essential oil from aromatic plants using the sun as the source of energy and using low cost and indigenous materials. The rate of extraction varies with the plant samples and the extraction process can last for 8 to 9 days. The percent yield of the plant extracts also varies with plants and it depends on the characteristics of the plant samples. The essential oil extracted through solar energy shows similar physical characteristics with the commercial oil.

It is recommended that the designed essential oil solar extractor is community friendly and can be assembled using indigenous materials. The volume of the extractor can be varied depending on its usability from community to industry based. It can be applied to almost all kinds of aromatic plants. The harvest of the essential oil can be done daily and kept the extracts is a tightly sealed dark containers to prevent them against deterioration and oxidation and to prolong its shelf life. The essential oil extracts can be used for a wide range of application in perfumery and aromatherapy industry. Percent yield of essential oil can be increased by increasing the amount of plant samples. A larger amount of plant sample is needed to extract a considerable amount of pure essential oil.

\section{References}

[1] Stuart Jr., G.U. (2017) List of Philippine Herbal Medicinal Plants. Philippine Medicinal Plants. StuartXchange - SX.

www.stuartxchange.org/CompleteList.html 
[2] Bhuiyan, N.I., et al. Sambong/Blumea balsamifera (Linn.) Dc./Blumea Camphor: (Medicinal Chemical Components in Volatile Oil from Blumea Balsamifera (L.) Dc. Bangladesh Journal of Botany, 38. www.stuartxchange.org/Sambong.html

[3] Milovanović, I.LJ., Misan Aleksandra Č. Sakač, M.B., Čabarkapa, I.S., Šarić, B.M., Matić, J.J. and Jovanov, P.T. Evaluation of A GC-MS Method for the Analysis of Oregano Essential Oil Composition. Food \& Feed Research Journal. www.fins.uns.ac.rs/index.php?mact=Magazines,cntnt01,details

[4] Masamba, W.R.L., Kamanula, J.F.M., Henry Elizabeth, M.T. and Nyirenda, G.K.C. (2003) Extraction and Analysis of Lemeongrass (Cymbopogon citratus) Oil: An Essential Oil with Potential to Control the Larger Grain Borere (Prostephanus truncates) in Stored Products in Malawi. Malawi Journal of Agricultural Science, 2.

[5] Naquvi, K.J., Ansari, S.H., Ali, M. and Najmi, A.K. (2014) Volatile Composition of Rosa Damascene Mill, (Rosacecae). Journal of Pharmacognosy and Phytochemistry, AkiNik Publications, 2, 177-181.

[6] Organic Facts. 17 Amazing Benefits of Lemongrass Essential Oil. www.OrganicFacts.net

[7] Gaspar, F., Santos, R. and King, M.B. (2000) Extraction of Essential Oils and Cuticular Waxes with Compressed $\mathrm{CO}_{2}$ : Effect of Matrix Pretreatment. 10/2000.

[8] Zougali, B.B., et al. (2010) Extraction of Essential Oils from Algerian Myrtle Leaves Using Instant Controlled Pressure Drop Technology. Journal of Chromatography $A, 1217,6134-6142$ https://doi.org/10.1016/j.chroma.2010.07.080

[9] Sani, N.S. and Rachmawati, R. Extracting Essential Oil From Jasmine By Using Enfleurage and Solvent Extraction Methods. http://digilib.its.ac.id/public/ITS-Undergraduate-23897-Abstract_en.pdf

[10] Rudy, N. (2007) Microwave Extraction of Essential Oils from "Penaga Lilin" (Mesua Ferrea L.) Leaves. Masters Thesis, Universiti Putra Malaysia.

[11] Sulong, M.F. (2006) A Rashid Extraction of Essential Oils from Jasmine Flower using Solvent Extraction Method. Official University College of Engineering \& Technology Malaysia: Tesis Sarjana Muda. http://iportal.ump.edu.my/lib/item?id=chamo:18893\&

[12] Hensel, O. and Anjum, M. (2008) Experimental Results of Essential Oils Extraction from Herbs using Solar Energy. University of Kassel, Agricultural Engineering.

[13] Flavourtech (2016) Spinning Cone Column. http://flavourtech.com/products/spinning-cone-column/

[14] Ha, H.K.P., Maridable, J., Gaspillo, P., Hasika, M., Malaluan, R. and Kawasaki, J. (2008) Essential Oil from Lemongrass Extracted by Supercritical Carbon Dioxide and Steam Distillation. The Philippine Agricultural Scientist, 91, 36-41.

[15] Nor, N.H.M., Khalisanni, K., Ahmad, A.W., Ibrahim, B., Maizatulnisa, O., Zaira, Z.C., Ruzaina, I. and Khalizani, K. (2012) Citronella Oil from Planting to Potential Perspectives. Novus Natural Science Research, 1, No. 2.

[16] Market Research Report. Essential Oil Market Analysis by Product (Orange, Corn Mint, Eucalyptus, Citronella, Peppermint, Lemon, Clove Leaf, Lime, Spearmint and Others), By Application (Medical, Food \& Beverage, Spa \& Relaxation, Cleaning \& Home and Others) and Segment Forecasts To 2024. http://www.grandviewresearch.com/

[17] DTI. Developing Rural Industries and Village Enterprises (DRIVE), in a Nutshell.

[18] Esoteric Oils CC and Sallamander Concepts (Pty) Ltd. 1998-2013.

[19] Bulgarian Rose Otto. Bulgarian Rose Absolute. https://www.bulgarianroseotto.com

[20] Tennant, E. (2013) How to Store Your Essential Oils. 
Submit or recommend next manuscript to OALib Journal and we will provide best service for you:

- Publication frequency: Monthly

- 9 subject areas of science, technology and medicine

- Fair and rigorous peer-review system

- Fast publication process

- Article promotion in various social networking sites (LinkedIn, Facebook, Twitter, etc.)

- Maximum dissemination of your research work

Submit Your Paper Online: Click Here to Submit

Or Contact service@oalib.com 